\title{
Improving Satellite-Based Subhourly Surface Rain Estimates Using Vertical Rain Profile Information
}

\author{
NOBUYUKi UTSUMi \\ Jet Propulsion Laboratory, California Institute of Technology, Pasadena, California, and Institute of Industrial Science, \\ The University of Tokyo, Tokyo, Japan \\ HYUNGJUN KIM \\ Institute of Industrial Science, The University of Tokyo, Tokyo, Japan \\ F. JOSEPH TURK AND ZIAD. S. HADDAD \\ Jet Propulsion Laboratory, California Institute of Technology, Pasadena, California
}

(Manuscript received 23 October 2018, in final form 20 March 2019)

\begin{abstract}
Quantifying time-averaged rain rate, or rain accumulation, on subhourly time scales is essential for various application studies requiring rain estimates. This study proposes a novel idea to estimate subhourly timeaveraged surface rain rate based on the instantaneous vertical rain profile observed from low-Earth-orbiting satellites. Instantaneous rain estimates from the Tropical Rainfall Measuring Mission (TRMM) Precipitation Radar (PR) are compared with 1-min surface rain gauges in North America and Kwajalein atoll for the warm seasons of 2005-14. Time-lagged correlation analysis between PR rain rates at various height levels and surface rain gauge data shows that the peak of the correlations tends to be delayed for PR rain at higher levels up to around 6-km altitude. PR estimates for low to middle height levels have better correlations with timedelayed surface gauge data than the PR's estimated surface rain rate product. This implies that rain estimates for lower to middle heights may have skill to estimate the eventual surface rain rate that occurs 1-30 min later. Therefore, in this study, the vertical profiles of TRMM PR instantaneous rain estimates are averaged between the surface and various heights above the surface to represent time-averaged surface rain rate. It was shown that vertically averaged PR estimates up to middle heights $(\sim 4.5 \mathrm{~km})$ exhibit better skill, compared to the PR estimated instantaneous surface rain product, to represent subhourly $(\sim 30 \mathrm{~min})$ time-averaged surface rain rate. These findings highlight the merit of additional consideration of vertical rain profiles, not only instantaneous surface rain rate, to improve subhourly surface estimates of satellite-based rain products.
\end{abstract}

\section{Introduction}

Precipitation monitoring from space provides essential information for climate science as well as applications such as hydrology, agricultural studies, and disaster prevention. The Tropical Rainfall Measuring Mission (TRMM) satellite, launched in 1997, carried the first satellite-borne Precipitation Radar (TRMM PR). The capability of TRMM PR for three-dimensional observation of precipitation (Iguchi et al. 2000) enabled observations of the vertical structure of precipitation over the tropical latitudes. Currently, the Global Precipitation

\footnotetext{
Corresponding author: Nobuyuki Utsumi, utsumi@rainbow.iis.utokyo.ac.jp
}

Measurement (GPM) Core Observatory, with its DualFrequency Precipitation Radar (GPM DPR), is operating as the successor of the TRMM satellite covering a wider latitude region than TRMM. In addition to their contribution to climate science, TRMM PR- and GPM DPRbased precipitation data serve as standards for the GPM constellation precipitation retrievals from passive microwave (PMW) sensors on low-Earth-orbiting (LEO) satellites (Passive Microwave Algorithm Team Facility 2018; Kubota et al. 2017). These observations from each single LEO satellite provide instantaneous precipitation estimates along its orbit swath.

However, an instantaneous precipitation measurement does not offer appropriate representativeness in time, which is an important factor in certain applications. 
For example, hydrologic simulations generally assume a stationary condition for boundary conditions within each calculation step (e.g., $30 \mathrm{~min}$ ). Therefore, having a time-averaged representative value directly affects the simulation performance. To meet such needs, merged precipitation mapping products based on multisatellite observations have been developed, such as IMERG (Huffman et al. 2018), PERSIANN (Ashouri et al. 2015), GSMaP (Ushio et al. 2009), and CMORPH (Joyce and Xie 2011). Most of these techniques utilize instantaneous PMW-based precipitation products derived from LEO satellites, with the infrared (IR) observations from geostationary satellites used to fill spatiotemporal gaps between the PMW observations. PMW-based estimates from LEO are, in general, more reliable than IR-based estimates, and therefore they are weighted higher than the IR-based precipitation mapping products (Joyce and Xie 2011). However, since the observations from LEO are available only at the time of satellite overpass, they can only provide instantaneous estimates, not the timeaveraged value over the time window. If time-averaged precipitation rate on subhourly time scales can somehow be better estimated from instantaneous LEO satellite observations, it may have potential to improve the quality of merged precipitation mapping products.

It is known that satellite-based precipitation estimates above the surface level exhibit lagged correlations with the surface precipitation rate. Amitai et al. (2012) compared TRMM PR instantaneous rain rate for "near surface level," which is defined as the lowest radar range bin free from ground clutter, against 1-min temporal resolution rain gauge observations in a semiarid watershed in Arizona, the United States. They showed that the TRMM PR near surface rain rate has the largest correlation with rain gauges occurring several minutes after the satellite overpass. According to Seto et al. (2013), the near surface level of TRMM PR is generally around $500-2000 \mathrm{~m}$ above ground surface. Also, Seto et al. (2013) showed that TRMM PR extreme rain estimates at near surface level have the highest skill against 1-min surface gauge rain rates over Japan when the fall time for raindrops to travel from near surface level to ground is considered. Similar time-lagged correlation is investigated in the northeastern Indian subcontinent by Terao et al. (2017), which found high correlations between TRMM PR near surface rain and gauge around $300 \mathrm{~s}(\sim 5 \mathrm{~min})$ after the satellite overpass time. Tan et al. (2018) evaluated satellite radar-based (GPM DPR Ku) and PMW-based precipitation estimates (GMI) with rain gauge networks from eastern coast of Virginia, United States; a semiarid region in Arizona, United States; and the European Alps region in Austria. They showed that PMW-based precipitation rates also show time lags comparing to surface gauge observations. One possibility for this time lag is that the database used for the GPM PMW algorithm consists of satellite radarbased precipitation estimates, which have time lags due to hydrometeor fall time from near surface level to ground. These studies highlight that the precipitation rates at a certain height above ground is correlated with time-lagged (after satellite overpass) surface precipitation. This finding implies that the information for the precipitation rate above ground may have skills to estimate surface precipitation shortly after the satellite overpass (hereafter termed the "near future"), and improve the time-averaged accumulation.

Three-dimensional (3D) observation of the distribution of precipitation observed by ground radars has been used for "nowcasting," that is, short-term forecast within an hour timeframe. For example, a high-resolution precipitation nowcast system has been developed by Japan Meteorological Agency (Japan Meteorological Agency 2018). Along with a one-dimensional convective model, this system uses 3D extrapolation technique of water content. Otsuka et al. (2016) also developed a nowcasting system that uses a $3 \mathrm{D}$ vector of precipitation derived from 3D volume scan by a phased array ground radar.

In contrast to ground radar-based studies, which exploit temporally successive radar images, the LEO satellite observations do not provide continuous measurements to derive the 3D motion of the precipitation. However, the vertical precipitation information observed from LEO satellites may still have potential to infer surface precipitation for a short time after the satellite overpass. This may be true in particular under an idealized "undisturbed" state, which assumes that the precipitation hydrometeors fall to the ground without being significantly affected by factors that change the precipitation rate (e.g., coalescence, evaporation, horizontal displacement) (see Fig. 1 for the schematic image of this concept).

Based on this idea, we hypothesize that 1) upper-level precipitation rates have skill to infer near-future surface precipitation, and 2) the vertically averaged precipitation has better skill than simply using instantaneous surface precipitation rate, to represent subhourly time averages of surface precipitation rate. The first may be true only up to certain height. Therefore, it should be investigated to what height the precipitation has skill for representing surface precipitation subsequent to the satellite overpass. The second hypothesis can only be valid if the first one is true.

This study investigates these hypotheses and demonstrates the potential of using vertical precipitation profile information to improve the subhourly averaged 


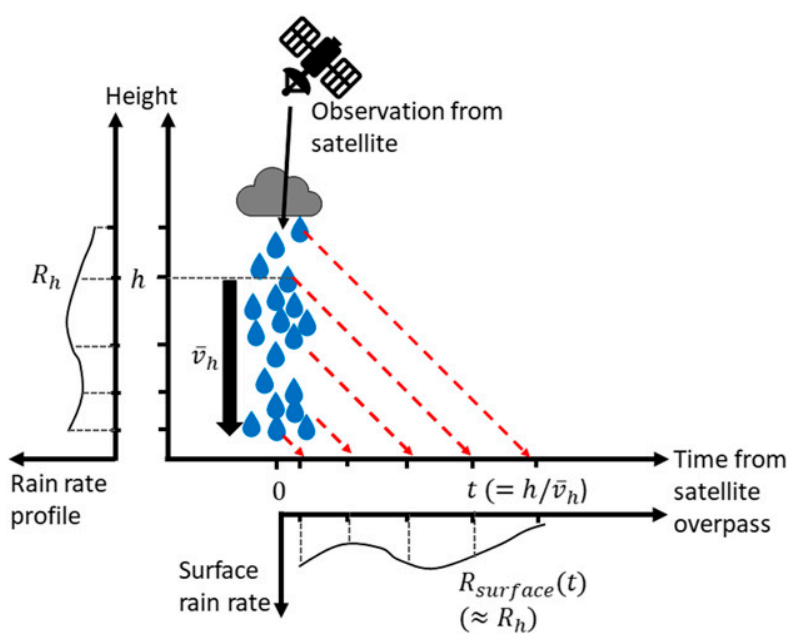

FIG. 1. Schematic image of the relationship between rain profile and surface rain rate under an idealized "undisturbed" state. Variable $t$ is the time from satellite overpass timing, $R_{h}$ is the rain rate at $h(\mathrm{~km})$ at the satellite overpass timing $(t=0)$, $R_{\text {surface }}(t)$ is the surface rain rate at the time of $t$, and $\bar{v}_{h}$ is the mean falling velocity of the raindrops at the height of $h$ falling to the surface.

surface precipitation. Note that the aim of this study is not to improve the "instantaneous" precipitation rate but to better estimate the representative value for "subhourly time-averaged" precipitation rate. In this study, as a test bed, we use precipitation profile and surface precipitation estimates from TRMM PR. To focus the analysis on liquid precipitation, the observations over relatively lower latitudes $\left(0^{\circ}-36^{\circ} \mathrm{N}\right)$ for warm season (April-October) are investigated.

Section 2 explains the data and methods. Correlations between upper-level TRMM PR precipitation and gauged surface precipitation rate are investigated in section 3. The skills of TRMM PR-based vertically averaged precipitation to represent time-averaged surface rain rate are assessed in section 4 and potential factors that may hinder the skill are discussed in section 5 . The results are summarized in section 6 , describing the potential of the proposed concept to improve the quantitative estimates of short-term satellite precipitation mapping products.

\section{Data and methods}

\section{a. Satellite-based rain profiles}

The data used in this study are the TRMM PR 2A25 PR Profile product (version 7; Iguchi et al. 2009) and the TRMM PR 2A23 PR Qualitative product (version 7; Awaka et al. 2009) for warm seasons (April-October) of 2005-14, which are obtained from the Japan Aerospace
Exploration Agency (JAXA) G-Portal system (https:// gportal.jaxa.jp/gpr/). TRMM PR observations cover relatively lower latitudes $\left(36^{\circ} \mathrm{S}-36^{\circ} \mathrm{N}\right)$ with 16 orbits per day on average. TRMM PR $2 \mathrm{~A} 25$ provides the estimated rainfall rate at the actual ground surface (e_SurfRain product) and the vertical profile of rain rate at 250-m vertical resolution. The e_SurfRain product is calculated assuming constant slope of attenuationcorrected radar reflectivity factor $(\mathrm{Ze})$ from the clutterfree echo to the surface (TRMM Precipitation Radar Team 2011). The $2 \mathrm{~A} 23$ product provides a classification of the rain type (stratiform or convective) information for each TRMM PR scan, of which the field of view (FOV) is approximately $5-\mathrm{km}$ diameter. These two TRMM PR products are so-called level-2 data, which are instantaneous estimates across the radar swath.

\section{b. Rain gauge observations and matchup with TRMM PR}

This study requires closely spaced in time ground observations before and after the satellite overpass in order to address time-lagged and time-averaged ground rainfall rate. To this end, the rain gauge observations with 1-min temporal resolution are obtained from TRMM and GPM Rain Gauge Data Archive (https:// gpm-gv.gsfc.nasa.gov/Gauge/). Because of the availability of observations before and after the satellite overpass, this dataset is more suitable for this study than the TRMM Validation Network Data based on ground radar observations, which provides only the single radar scan closest in time to the satellite overpass. The rain gauge dataset provides quality-controlled rain gauge data for the validation of TRMM observations from various gauge networks spread over North America, Kwajalein, Brazil, and Darwin. In this study, in order to reduce the effect of spatial variability of precipitation in the TRMM PR FOV, only matching cases which have more than three gauges located within $5 \mathrm{~km}$ radius from the center of the TRMM PR FOV are selected. The gauge observations within this radius are averaged and compared to TRMM PR observations. Although the threshold distance of $5 \mathrm{~km}$ is larger than the size of TRMM PR FOV (approximately $2.5-\mathrm{km}$ radius), it was chosen considering the balance of the sample size and matchup accuracy. Matchup cases are considered only when there is more than one rain observation in any of the gauge (from -15 to +30 min centered on satellite overpass time) and TRMM PR (from the near surface level to $8.5-\mathrm{km}$ height level and e_SurfRain). Eventually, 9356 cases for 404 gauges from six networks are selected (Table 1 and Fig. 2). 
TABLE 1. Summary of rain gauge networks.

\begin{tabular}{lcrr}
\hline \multicolumn{1}{c}{ Network } & Domain & No. of gauges & No. of cases \\
\hline N.Carolina-IPHEx, NC (NASA gauges) & $35.44^{\circ}-35.69^{\circ} \mathrm{N}, 83.59^{\circ}-82.57^{\circ} \mathrm{W}$ & 20 & 159 \\
N.Carolina-IPHEx, NC (Duke gauges) & $35.37^{\circ}-35.77^{\circ} \mathrm{N}, 83.26^{\circ}-82.92^{\circ} \mathrm{W}$ & 36 & 191 \\
Texas-Harris County (HAR) & $29.46^{\circ}-30.43^{\circ} \mathrm{N}, 95.89^{\circ}-94.99^{\circ} \mathrm{W}$ & 190 & 32 \\
Florida-Kennedy (KSC) & $28.42^{\circ}-28.70^{\circ} \mathrm{N}, 80.75^{\circ}-80.53^{\circ} \mathrm{W}$ & 113 & 1356 \\
Florida-South Florida WMD (SFL) & $25.21^{\circ}-28.31^{\circ} \mathrm{N}, 81.88^{\circ}-80.12^{\circ} \mathrm{W}$ & 13 & 2506 \\
Kwajalein-KWA & $9.39^{\circ}-9.40^{\circ} \mathrm{N}, 167.47^{\circ}-167.47^{\circ} \mathrm{E}$ & 394 & 9356 \\
Total & - & & 404 \\
\hline
\end{tabular}

\section{c. Vertical and time averaging}

This study investigates the skill of vertically averaged satellite rain rate to represent subhourly time averages of surface rain rate. The vertically averaged rain rate is computed by simply averaging the TRMM PR instantaneous rain profile, which has $250-\mathrm{m}$ vertical resolution, from the surface to a certain height. This height will be called the "averaging height" herein. The e_SurfRain product is used as the rain rate at the surface in this averaging. The bins containing missing data are excluded from the averaging. For each satellite and rain gauge matchup case, the 1-min rain gauge observations within $5 \mathrm{~km}$ from the center of the TRMM PR FOV are spatially averaged to construct time series of 1-min rain rate before and after the satellite overpass. Using this sequence of 1-min data, the time-averaged surface rain rate is computed by averaging these data between the satellite overpass time and a certain time after the overpass.

\section{d. Evaluation metrics}

The agreement between satellite-based rain rate and gauge-based rain rate is evaluated in terms of three metrics; correlation coefficient (CC), bias ratio, and root-mean-square error (RMSE). Each of the metrics is defined as follows:

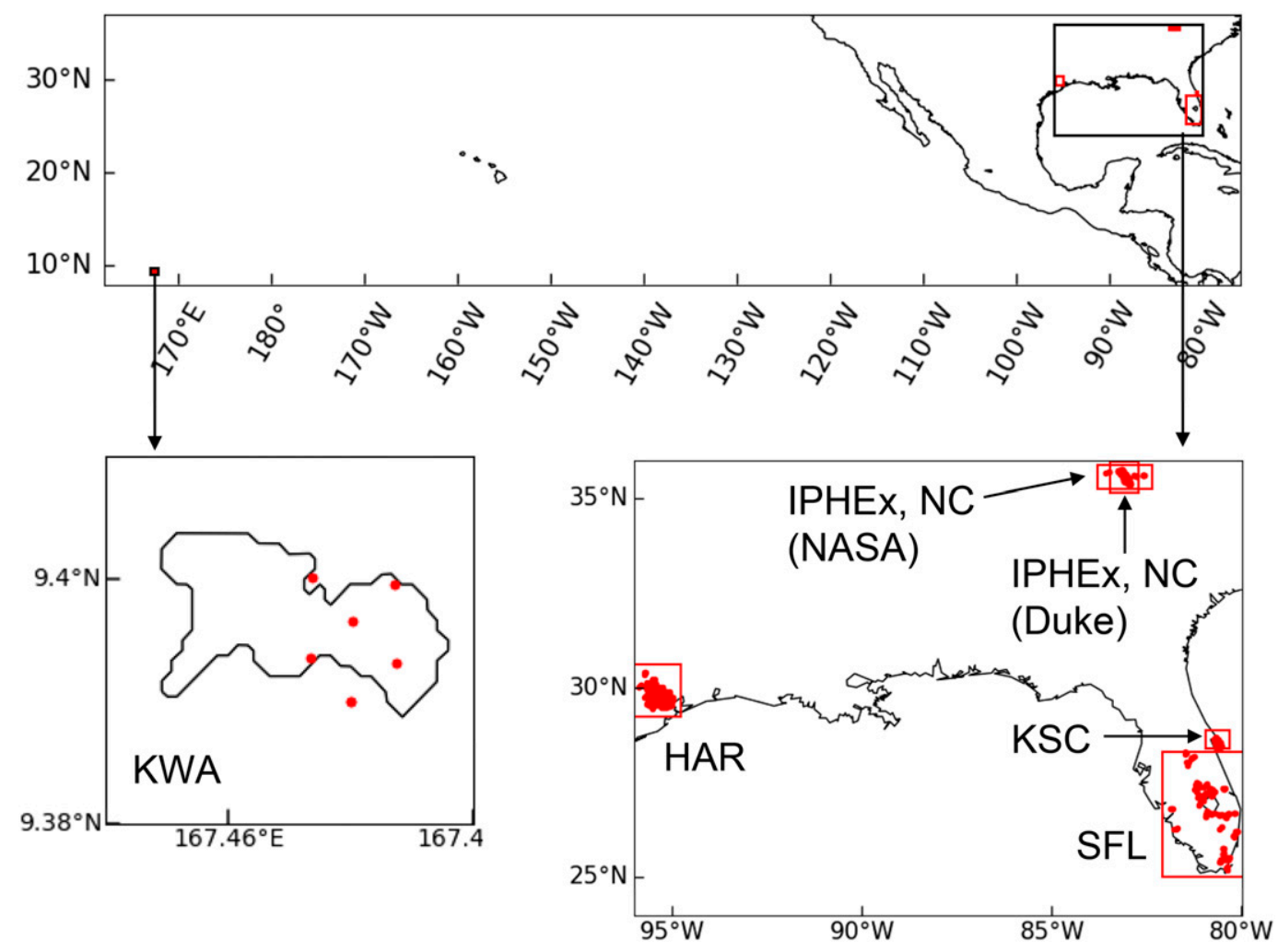

FIG. 2. Locations of rain gauge networks. Red points indicate the rain gauge locations. Some of the rain gauges are installed in close proximity such that the points are overlapping (e.g., in KWA). Also, the IPHEx, NC (NASA), and IPHEx, NC (Duke), domains are overlapping. 

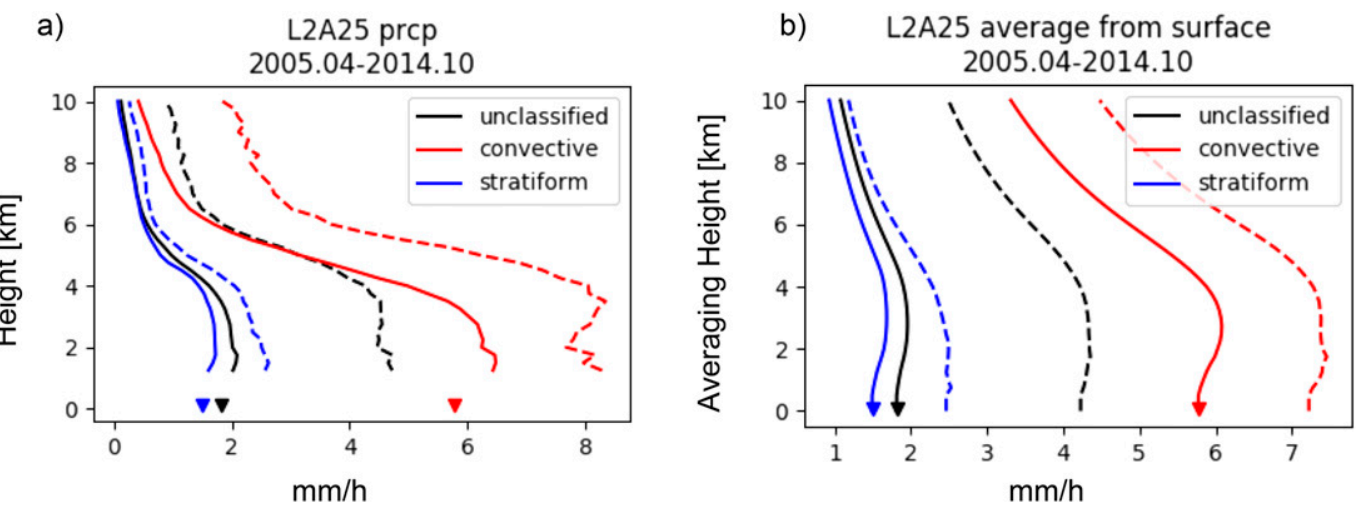

FIG. 3. (a) Vertical profile of TRMM PR rain rate $\left(\mathrm{mm} \mathrm{h}^{-1}\right)$. (b) Vertically averaged rain rate (averaged from surface to each height). Solid and dashed lines show mean and standard deviation at each height, respectively. Reversed triangles show estimated surface rain rate (e_SurfRain) of the TRMM PR 2A25 product.

$$
\mathrm{CC}=\frac{\sum_{i}\left(x_{i}-\bar{x}\right)\left(y_{i}-\bar{y}\right)}{\sqrt{\sum_{i}\left(x_{i}-\bar{x}\right)^{2}} \sqrt{\sum_{i}\left(y_{i}-\bar{y}\right)^{2}}},
$$

bias ratio $=\frac{\bar{x}-\bar{y}}{\bar{y}}$, and

$$
\operatorname{RMSE}=\sqrt{\frac{1}{n} \sum_{i}\left(x_{i}-y_{i}\right)^{2}},
$$

where $x_{i}$ and $y_{i}$ are the satellite-based rain rate and the rain gauge-based rain rate for $i$ th matchup case, respectively; $n$ is the number of matchup cases; and the overbar indicates the average over all matchup cases.

\section{Correlations between upper-level rain and time-delayed surface rain}

In this section, the skill of TRMM PR rain rates above ground level to infer time-delayed surface rain rates is investigated. Figure 3 a shows the mean profile of the TRMM PR rain rate. The average rain rate of unclassified rain (i.e., without rain type classification) is approximately $2 \mathrm{~mm} \mathrm{~h}^{-1}$ up to $3.5 \mathrm{~km}$ and it decreases sharply around $3.5-5 \mathrm{~km}$. The standard deviation shows there is large variability of rain rate particularly in the low level heights.

Figure 4 shows the correlation coefficient between TRMM PR rain rate at various heights and time-delayed rain gauge observations. The TRMM PR e_SurfRain product (black dashed line in Fig. 4) has a peak CC with the gauge observations at the time near the satellite overpass. As the TRMM PR observation height becomes higher, the peak in the $\mathrm{CC}$ tends to be delayed. For example, the CC peak for $4 \mathrm{~km}$ is observed around $6-7 \mathrm{~min}$ after the satellite overpass (Fig. $4 \mathrm{a}$ ).
The time delay of CC peaks increases up to 7-8 min at the heights of 5-6 km. Rain rates at low levels $(2-3 \mathrm{~km})$ show slightly higher correlations with rain gauges than e_SurfRain, for a delay of 2-17 min after the satellite overpass.

Figures $4 \mathrm{~b}$ and $4 \mathrm{c}$ show the results of the same analysis when the rain is separated into convective and stratiform rain type, respectively, identified by the TRMM PR 2A23 rain type classification product. Both rain types are also found to have a delay in the peak CC. For both rain types, the maximum delays are around $8-9 \mathrm{~min}$ corresponding to $5-6-\mathrm{km}$ height. For convective rain, rain rates at the $2-3-\mathrm{km}$ level tend to have a higher CC than e_SurfRain, for a delay of 1-30 min after the satellite overpass. Rain rates at 4-5-km height also show a higher CC than e_SurfRain for a range of 4-18-min delay. For stratiform rain, the CC between 2- and $5-\mathrm{km}$ height is higher than e_SurfRain for a delay of 8-30 min after the satellite overpass. For longer delays, stratiform rain tends to have larger improvement of CC compared to e_SurfRain than of convective rain. This can be because stratiform rain is more likely to obey the "undisturbed" state (defined above) than convective rain.

Previous studies have reported time delays in the CC peak using TRMM PR near-surface rain (Amitai et al. 2012; Seto et al. 2013) and GPM DPR estimated surface rain (Tan et al. 2018). Such time delays are due to the fall time for the raindrops to reach the surface. Our findings suggest that a time delay is found for upper-level rain rates as well, not only the lowest range bin of the satellite radar-based rain rate estimation.

For unclassified rain cases (i.e., without rain type classification), the $\mathrm{CC}$ peak for $5-\mathrm{km}$ height rain rate is located at a delay of $8 \mathrm{~min}$ after the satellite overpass. 

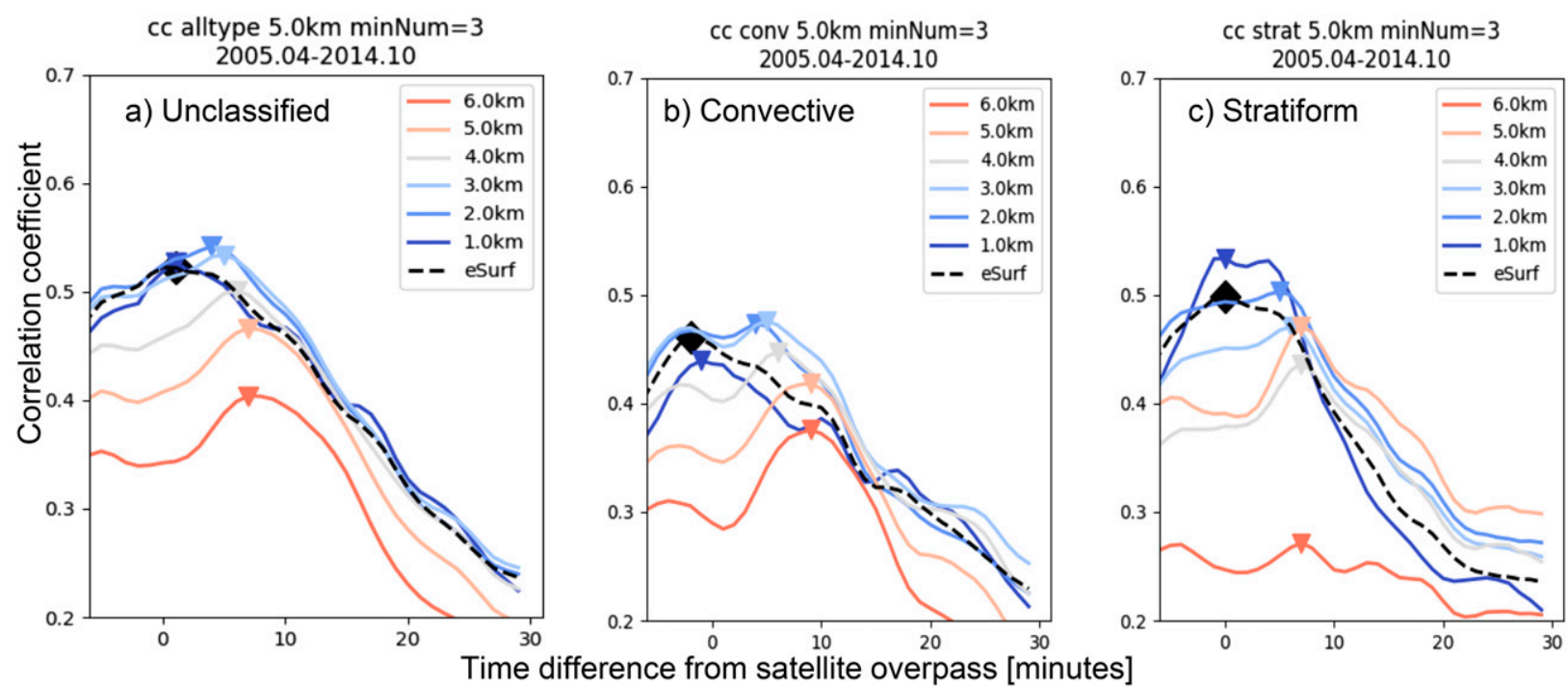

FIG. 4. Correlation coefficient between time-delayed gauge rain and TRMM PR rain rate at different heights. (a) Unclassified rain. (b) Convective rain. (c) Stratiform rain. Black dashed lines are e_SurfRain. Colored lines are the CC for upper-level TRMM PR rain rates. Moving average with 5-min window with 1-2-3-2-1 weight is applied to the lines in order to reduce the noise.

Assuming on average a precipitation-sized hydrometeor at 5-km height takes about $8 \mathrm{~min}$ to reach the ground, the average fall velocity is about $16.7 \mathrm{~m} \mathrm{~s}^{-1}$. This is significantly faster than $4.17 \mathrm{~m} \mathrm{~s}^{-1}$ assumed in a previous study (Seto et al. 2013), and not physically realistic (even faster than the terminal velocity of $10-12 \mathrm{~m} \mathrm{~s}^{-1}$ of large raindrops; Beard 1976). Also, the shift of the CC peak is not proportional to the travel distance (i.e., rain height), and the CC shift saturates around 5-6-km height with about a 7-9-min delay. These findings imply that the CC delay for relatively higher altitude is not solely determined by the falling velocity of the hydrometeors, but may also controlled by other factors, such as drop size distribution variability and horizontal displacement by wind.

\section{Improving subhourly rain estimates}

\section{a. Vertically averaged satellite rain rate and time-averaged gauge rain rate}

In the previous section, it was found that TRMM PR rain rates up to middle troposphere heights $(\sim 6 \mathrm{~km})$ exhibit skill to infer near-future surface rain rate. This implies the potential of using the vertically averaged instantaneous rain rate as a surrogate for temporal averaging of surface rain rates. Figure 5 shows the CC between vertically averaged TRMM PR rain rates and the time averaged surface rain gauge observations. The average and standard deviation of the vertically averaged rain rate is shown in Fig. $3 \mathrm{~b}$ for reference.

For 1-min rain, 2-km vertically averaged rain (i.e., average from surface to $2 \mathrm{~km}$ ) exhibits the highest CC (Fig. 5).

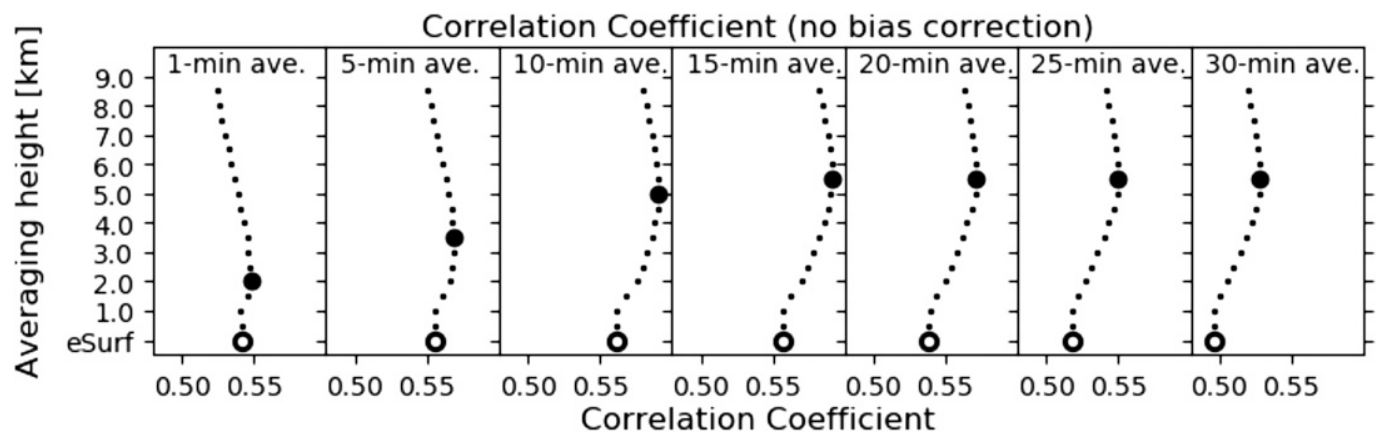

FIG. 5. Correlation coefficient between the time-averaged gauge rain rate and vertically averaged TRMM $\mathrm{PR}$ rain rate. The solid circle indicates the averaging height that gives the best correlation coefficient. The open circle indicates the metric for the estimated surface rain rate (e_SurfRain) from the TRMM PR 2A25 product. 

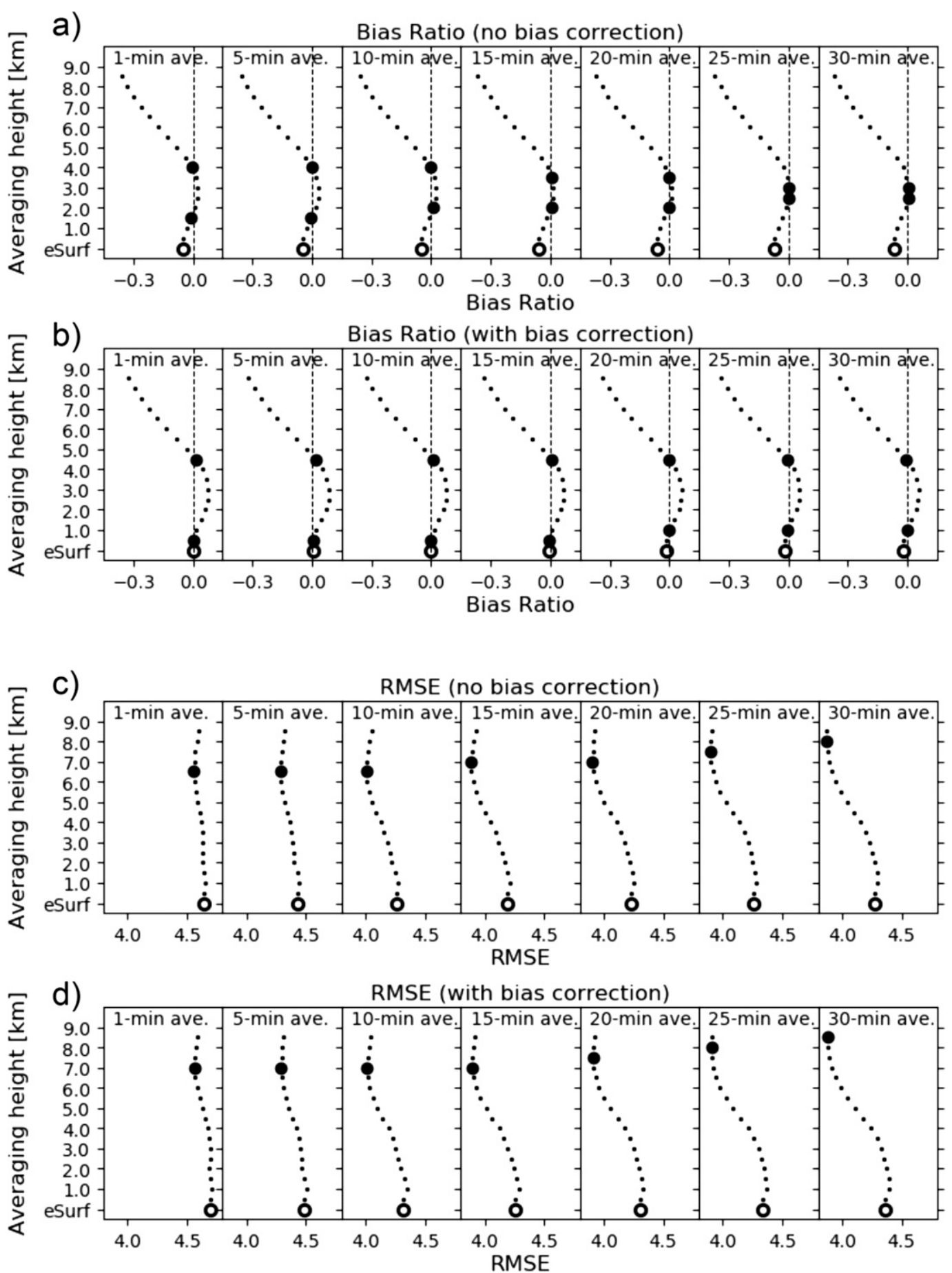

FIG. 6. As in Fig. 5, but for (a),(b) bias ratio and (c),(d) RMSE. Panels (a) and (c) represent no bias correction, and (b) and (d) are with bias correction. For bias ratio, the two best averaging heights (bias ratio closest to zero) are indicated by solid circles.

As the averaging time of the surface rain become longer (up to $15 \mathrm{~min}$ ), the best averaging height becomes higher up to $5.5 \mathrm{~km}$. For time scales longer than $15 \mathrm{~min}$, it keeps the best averaging height saturated at $5.5 \mathrm{~km}$. For a 30-min average, the CC is $6.4 \%$ higher than e_SurfRain, using a surface to $5.5-\mathrm{km}$ averaged satellite rain rate.

Figure 6a shows the bias ratio of the vertically averaged rain rate compared to the time averaged rain gauge 
data. Note that the absolute bias ratio close to zero suggests good agreement of TRMM PR rain with gauge rain. In the distribution of the 1-min rain bias ratio, two local minima (measured by the displacement from zero $x$ axis) of absolute bias ratio are found, when averaging up to $1.5-\mathrm{km}$ and to $4.0-\mathrm{km}$ heights, respectively. Meanwhile, for a 30-min average gauged rain, these same local minima of absolute bias ratio are found when averaging up to near $2.5 \mathrm{~km}$ and to $3.0 \mathrm{~km}$. When averaged up to $2.5 \mathrm{~km}$, the absolute bias ratio for 30 -min rain is reduced significantly (by nearly $96 \%$ ) compared to the e_SurfRain. This means that the instantaneous rain rate averaged up to $2.5-3.0 \mathrm{~km}$ exhibits better agreement with 30-min surface rain, in terms of bias ratio, than e_SurfRain.

Figure 6a indicates that e_SurfRain tends to underestimate 1-min averaged gauge rain, suggesting that there may be a systematic bias in e_SurfRain. Figure $6 \mathrm{~b}$ shows the same analysis as shown in Fig. 6a, but for TRMM PR after applying a simple bias correction technique defined as

$$
R^{\prime}(h)=a R(h),
$$

where

$$
a=\overline{R_{1 \min }} / \overline{R_{\mathrm{eSurf}}},
$$

where $R(h)$ and $R^{\prime}(h)$ are the original and the bias corrected TRMM PR rain rate at $h(\mathrm{~km})$ height, $a$ is correction factor, $R_{1 \text { min }}$ is 1-min gauge rain rate intersecting the satellite overpass time, $R_{\mathrm{eSurf}}$ is e_SurfRain, the overbar indicates the average over all matchup cases. By definition, when the bias correction is applied, e_SurfRain has equal value to the 1-min gauged rain. For 30-min average rain rate, however, the minimum bias is found at the averaging height up to $1.0 \mathrm{~km}$, with a secondary minimum at $4.5 \mathrm{~km}$ (Fig. 6b). This result shows that even if such a systematic bias in the TRMM PR e_SurfRain is assumed, a vertically averaged rain rate still has better skill than the instantaneous e_SurfRain surface estimation for a rain rate representing a time range (e.g., $30 \mathrm{~min}$ ). Note that the bias correction as defined by Eqs. (4) and (5) does not affect CC.

Figures $6 \mathrm{c}$ and $6 \mathrm{~d}$ show RMSEs of vertically averaged TRMM PR and time-averaged gauge rain rate without (Fig. 6c) and with (Fig. 6d) bias correction. The difference of RMSE among different averaging heights is larger for longer time scales (e.g., 30-min average) than in shorter time scales (e.g., 1-min average). For 30-min averaging, the RMSE has the smallest value when averaged up to $8.0 \mathrm{~km}(8.5 \mathrm{~km})$ without (with) bias correction. The RMSE of noncorrected $8.0-\mathrm{km}$ averaged (corrected $8.5 \mathrm{~km}$ averaged) rain rate is $9.3 \%(10.8 \%)$
TABLE 2. Best averaging heights for representing 30-min mean surface rain rate and change of metrics compared to e_SurfRain.

\begin{tabular}{llccc}
\hline \hline & & Unclassified & Convective & Stratiform \\
\hline $\mathrm{CC}$ & Height $(\mathrm{km})$ & 5.5 & 6.0 & 6.0 \\
& (Change) & $(+6.4 \%)$ & $(+9.6 \%)$ & $(+14.2 \%)$ \\
Bias ratio & Height $(\mathrm{km})$ & 2.5 & 7.0 & 4.0 \\
& (Change) & $(-95.9 \%)$ & $(-92.5 \%)$ & $(-97.7 \%)$ \\
RMSE & Height $(\mathrm{km})$ & 8.0 & 8.5 & 5.5 \\
& $($ Change $)$ & $(-9.3 \%)$ & $(-12.5 \%)$ & $(-6.4 \%)$ \\
\hline
\end{tabular}

better than e_SurfRain. This suggests the vertically averaged instantaneous rain outperforms e_SurfRain for representing subhourly average surface rain rate in terms of RMSE.

\section{b. Performance of vertically averaged rain rate to represent subhourly surface rain rate}

Table 2 shows the averaging heights that give the best skill for 30-min rain for each of the three metrics (CC, bias ratio, RMSE). The best averaging height for $\mathrm{CC}$ for the unclassified rain case is $5.5 \mathrm{~km}$. Even when the rain events are classified by rain types (convective and stratiform), the best heights for CC are almost the same $(5.5-6.0 \mathrm{~km})$. Meanwhile, for the bias ratio, the best averaging height takes a wide range; $2.5,4.0$, and $7.0 \mathrm{~km}$ for unclassified, stratiform, and convective rain, respectively. When RMSE is used as a metric, the best averaging height is high $(8.0-8.5 \mathrm{~km})$ for unclassified and convective cases and middle height $(5.5 \mathrm{~km})$ for the stratiform rain case.

Since the best averaging height varies for different metrics, there is not a single optimal way to determine the averaging height. In the analysis from this point on, $4.5 \mathrm{~km}$ is chosen as the averaging height of the TRMM PR observation to represent 30-min mean surface rain rate. This is similar to the climatological mean of warm season freezing level in the low-latitude CONUS region (Harris et al. 2000).

Table 3 shows the metrics, for representing 30-min surface rain, of the TRMM PR instantaneous estimation (i.e., e_SurfRain) and the rain rate vertically averaged up to $4.5 \mathrm{~km}$. They are evaluated against rain gauges for various surface rain intensity classes, as indicated on the left side of Table 3. The intensity classes are determined based on the TRMM PR e_SurfRain. By using a $4.5-\mathrm{km}$ average rain, compared to e_SurfRain, the CC improves in all intensity classes. Both bias ratio and RMSE are improved in all intensity classes, except $5-10 \mathrm{~mm} \mathrm{~h}^{-1}$ range for bias ratio, and $10-20 \mathrm{~mm} \mathrm{~h}^{-1}$ range for RMSE, while the improvement of RMSE is not large in general. Although some of these improvements are marginal (e.g., RMSE for the lowest $0.1-1 \mathrm{~mm} \mathrm{~h}^{-1}$ range) given 


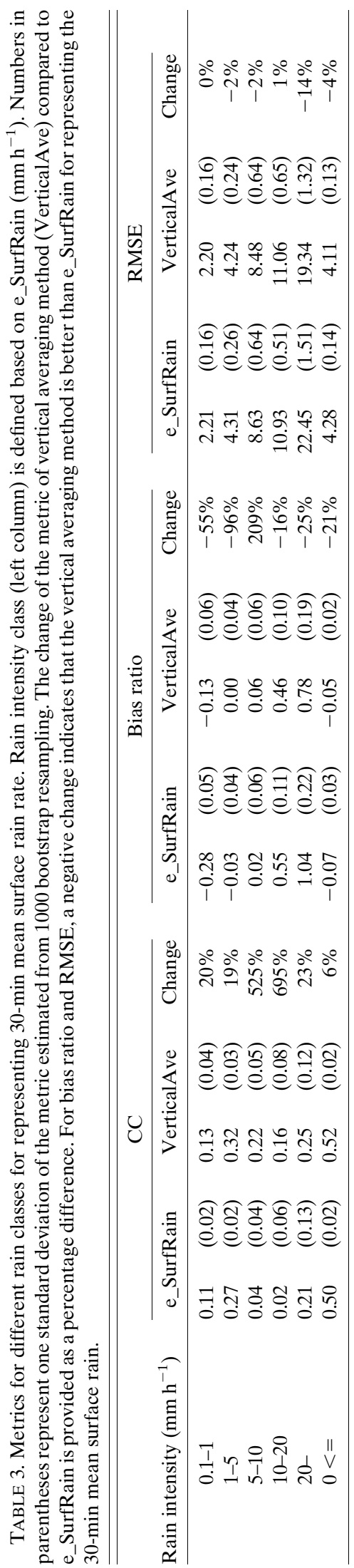

the uncertainty of the estimated metrics (measured by bootstrap standard deviation), the improvements of metrics found in most intensity classes suggest the merit of using the proposed vertical averaging method to improve time-averaged rain rate accumulation.

In Table 4, the metrics are shown for each of the different rain types (i.e., unclassified, convective, and stratiform). If vertically averaged rain up to $4.5 \mathrm{~km}$ is used instead of e_SurfRain, the CC improves in all three rain types. The largest improvement is found for stratiform rain type, where $\mathrm{CC}$ increases by $11 \%$. Bias ratio improves for all three cases. The largest improvement for bias ratio is found for stratiform types, where the bias ratio improves by $69 \%$. The RMSE also improves for all three cases, with the best improvement found for stratiform rain types where RMSE decreases by $5 \%$. Overall, vertical averaging outperforms the instantaneous estimation to represent the 30-min rain rate estimation, and is especially effective for stratiform rain type.

\section{Potential factors affecting surface rain estimation}

In principle, if the distribution of fall velocities of the raindrops is constant and it is not affected by any disturbance such as evaporation and horizontal displacement, the near-future surface rain rate can be projected from the rain rate at upper levels (Fig. 1). However, in reality, the raindrops experience various processes that hinder such a simple projection.

Physical processes such as raindrop evaporation, coalescence, and breakup can affect the falling velocity by changing the drop size distribution (Hu and Srivastava 1995). The evaporation of raindrops changes total amount of water falling to the ground as well. Although it is difficult to account for all these complex processes, the effect of the evaporation can be indirectly addressed by considering the relative humidity of the lower atmosphere. To evaluate the effect of humidity in the lower atmosphere, the performance of the proposed method for estimating 30-min average rain is investigated for dry cases [relative humidity $(\mathrm{RH})<70 \%$ ] and humid cases $(\mathrm{RH} \geq 70 \%$; Table 5) separately. $\mathrm{RH}$ is prepared for every hour over $0.50^{\circ} \times 0.625^{\circ}$ grids based on surface pressure, specific humidity and air temperature obtained from the Modern-Era Retrospective Analysis for Research and Applications, version 2 (MERRA-2; Gelaro et al. 2017). The vertical rain profile at the location of the TRMM PR observation is paired to the nearest spatial/temporal MERRA-2 products. For the dry events, the bias ratio of the $4.5-\mathrm{km}$ averaging rain becomes worse relative to the existing TRMM e_SurfRain product, but vertical averaging improves $\mathrm{CC}$ and $\mathrm{RMSE}$ 
TABLE 4. As in Table 3, but the rain cases are classified by rain types: unclassified (all rain types), convective, and stratiform. Rain types are identified from the TRMM $2 \mathrm{~A} 23$ product.

\begin{tabular}{|c|c|c|c|c|c|c|c|c|c|c|c|c|c|c|c|}
\hline \multirow[b]{3}{*}{ Unclassified } & \multicolumn{5}{|c|}{$\mathrm{CC}$} & \multicolumn{5}{|c|}{ Bias ratio } & \multicolumn{5}{|c|}{ RMSE } \\
\hline & \multicolumn{2}{|c|}{ e_SurfRain } & \multicolumn{2}{|c|}{ VerticalAve } & \multirow{2}{*}{$\begin{array}{c}\text { Change } \\
+6 \%\end{array}$} & \multicolumn{2}{|c|}{ e_SurfRain } & \multicolumn{2}{|c|}{ VerticalAve } & \multirow{2}{*}{$\begin{array}{c}\text { Change } \\
-21 \%\end{array}$} & \multicolumn{2}{|c|}{ e_SurfRain } & \multicolumn{2}{|c|}{ VerticalAve } & \multirow{2}{*}{$\begin{array}{c}\text { Change } \\
-4 \%\end{array}$} \\
\hline & 0.50 & $(0.02)$ & 0.52 & $(0.02)$ & & -0.07 & $(0.03)$ & -0.05 & $(0.02)$ & & 4.28 & $(0.14)$ & 4.11 & $(0.13)$ & \\
\hline Convective & 0.44 & $(0.03)$ & 0.48 & $(0.03)$ & $+9 \%$ & 0.30 & $(0.05)$ & 0.28 & $(0.05)$ & $-7 \%$ & 8.21 & $(0.32)$ & 7.87 & $(0.32)$ & $-4 \%$ \\
\hline Stratiform & 0.42 & $(0.04)$ & 0.47 & $(0.03)$ & $+11 \%$ & -0.10 & $(0.03)$ & -0.03 & $(0.03)$ & $-69 \%$ & 3.48 & $(0.23)$ & 3.30 & $(0.15)$ & $-5 \%$ \\
\hline
\end{tabular}

even for dry events. Despite possible miscollocation between satellite observation and model-based humidity of MERRA-2, these results suggest that the proposed method retains its skill for 30-min surface rain even for the environment where raindrops are prone to evaporation.

Horizontal displacement of raindrops by wind also hinders the performance of the time-averaged rain estimation since the proposed method in this study assumes that raindrops fall vertically without slanting. In this study, we assume the effect of a several kilometers horizontal displacement of raindrops is negligible as our analysis based on multiple (at least three) collecting gauges within $5 \mathrm{~km}$ from the center of TRMM PR FOV. However, it should be noted that very strong wind gusts may be able to affects the results by significant horizontal displacement.

In this study, we did not consider using a vertical weight profile; rather, a simple arithmetic mean was used for the vertical averaging. The vertical weights could be set considering the factors discussed above, such as atmospheric humidity and horizontal wind speed, and also typical rain profiles of the regions/seasons (Hirose and Nakamura 2004; Kobayashi et al. 2018). To investigate the potential of weighted averaging, mathematically optimal weights in terms of CC are estimated with canonical correlation analysis (CCA; Hotelling 1936). The CCA method finds a set of weights that maximizes the $\mathrm{CC}$ between the weighted vertical average of rain rate and the time averaged surface rain rate. Using this analysis, the maximum $\mathrm{CC}$ was found to be 0.55 . This number indicates the maximum CC attainable by using a weighting averaging approach. However, the optimal weight profile calculated in this way is not useful to interpret the physical meaning of the weight profile since some of the weights are negative. Therefore, we leave investigating the weights with physical meaning as future study.

\section{Summary and concluding remarks}

The results of this study are summarized in two main conclusions. First, the analysis from section 3 showed that satellite-based radar rain estimates at low to middle height levels (up to $6 \mathrm{~km}$ ) demonstrated skill to infer eventual (near-future) surface rain rate up to $30 \mathrm{~min}$ in the future. The aboveground precipitation profile from the satellite radar carries information on the near-future surface rain rate. Second, the analysis from section 4 showed that vertically averaged instantaneous rain rate better represents subhourly surface rain rate, when compared to the estimated surface rain product (e_SurfRain) of the TRMM PR $2 \mathrm{~A} 25$ product. It is found that $4.5-\mathrm{km}$ averaged TRMM PR rain outperforms e_SurfRain to estimate 30-min surface rain, for all rain types (i.e., unclassified, convective, and stratiform).

By intent, this study focuses on warm season in the relatively lower latitudes. It assures that most of the precipitation analyzed in this study is liquid phase. Since cold season precipitation has different microphysics, and snow is more susceptible to horizontal displacement by wind, the proposed method may work differently for cold seasons and cold regions. To investigate such aspect of solid phase precipitation, an extended study for other seasons and regions is required.

The result of this study is encouraging toward improvements of merged satellite precipitation products in two regards. First, although only one satellite radar (GPM DPR) dedicated to precipitation monitoring is currently operating, some future constellations of

TABLE 5. As in Table 3, but the rain cases are classified by atmospheric humidity conditions. Dry $=$ low-level relative humidity $<70 \%$. Humid $=$ low-level relative humidity $\geq 70 \%$.

\begin{tabular}{|c|c|c|c|c|c|c|c|c|c|c|c|c|c|c|c|}
\hline \multirow[b]{3}{*}{ Dry } & \multicolumn{5}{|c|}{$\mathrm{CC}$} & \multicolumn{5}{|c|}{ Bias ratio } & \multicolumn{5}{|c|}{ RMSE } \\
\hline & \multicolumn{2}{|c|}{ e_SurfRain } & \multicolumn{2}{|c|}{ VerticalAve } & \multirow{2}{*}{$\begin{array}{c}\text { Change } \\
+8 \%\end{array}$} & \multicolumn{2}{|c|}{ e_SurfRain } & \multicolumn{2}{|c|}{ VerticalAve } & \multirow{2}{*}{$\begin{array}{c}\text { Change } \\
+25 \%\end{array}$} & \multicolumn{2}{|c|}{ e_SurfRain } & \multicolumn{2}{|c|}{ VerticalAve } & \multirow{2}{*}{$\begin{array}{c}\text { Change } \\
-4 \%\end{array}$} \\
\hline & 0.44 & $(0.06)$ & 0.48 & $(0.04)$ & & 0.22 & $(0.07)$ & 0.28 & $(0.07)$ & & 4.19 & $(0.18)$ & 4.04 & $(0.18)$ & \\
\hline Humid & 0.52 & $(0.02)$ & 0.55 & $(0.02)$ & $+6 \%$ & -0.15 & $(0.03)$ & -0.14 & $(0.02)$ & $-3 \%$ & 4.30 & (0.17) & 4.12 & $(0.16)$ & $-4 \%$ \\
\hline
\end{tabular}


multiple small satellites with precipitation radar capabilities are being discussed (Tanelli et al. 2019; Haddad et al. 2017; Muraki 2017). The idea proposed in this study can be directly applied to rain estimates obtained by such satellite radar constellations and it should improve merged surface rain mapping products.

Second, some of the satellite PMW-based precipitation retrievals use databases for the coincident brightness temperature and radar-based precipitation profiles, which have potential to estimate vertical profiles of precipitation rate (Kummerow et al. 2015; Turk et al. 2018). For example, NASA's GPROF precipitation retrieval algorithm for GPM (Kummerow et al. 2015) provides an estimate of the vertical profile of precipitation hydrometeors. If such PMW-based algorithms retrieve rain profiles adequately, the vertical averaging method can be considered to improve subhourly rain rate estimates by PMW observations, which potentially leads to reduce such known systematic bias dependent on atmospheric states (e.g., cloud types; Utsumi and Kim 2018) within multisatellite merged precipitation mapping products.

Acknowledgments. This work was supported in part by the Eighth Research Announcement of Precipitation Measurement Mission of Japan Aerospace Exploration Agency under solicitation 17RS-TK003905, JSPS KAKENHI under Grants JP16H06725 and 18KK0117, and the JSPS Overseas Research Fellowships. FJT and ZSH acknowledge support from NASA's Precipitation Measurements Mission (PMM) under solicitation NNH15ZDA001N-PMM. This work was carried out at the Jet Propulsion Laboratory, California Institute of Technology, under a contract with NASA.

\section{REFERENCES}

Amitai, E., C. L. Unkrich, D. C. Goodrich, E. Habib, and B. Thill, 2012: Assessing satellite-based rainfall estimates in semiarid watersheds using the USDA-ARS Walnut Gulch gauge network and TRMM PR. J. Hydrometeor., 13, 1579-1588, https:// doi.org/10.1175/JHM-D-12-016.1.

Ashouri, H., K.-L. Hsu, S. Sorooshian, D. K. Braithwaite, K. R. Knapp, L. D. Cecil, B. R. Nelson, and O. P. Prat, 2015: PERSIANN-CDR: Daily precipitation climate data record from multisatellite observations for hydrological and climate studies. Bull. Amer. Meteor. Soc., 96, 69-83, https://doi.org/ 10.1175/BAMS-D-13-00068.1.

Awaka, J., T. Iguchi, and K. Okamoto, 2009: TRMM PR standard algorithm $2 \mathrm{~A} 23$ and its performance on bright band detection. J. Meteor. Soc. Japan Ser. II, 87A, 31-52, https://doi.org/ 10.2151/jmsj.87A.31.

Beard, K. V., 1976: Terminal velocity and shape of cloud and precipitation drops aloft. J. Atmos. Sci., 33, 851-864, https:// doi.org/10.1175/1520-0469(1976)033<0851:TVASOC $>$ 2.0. $\mathrm{CO} ; 2$.
Gelaro, R., and Coauthors, 2017: The Modern-Era Retrospective Analysis for Research and Applications, version 2 (MERRA-2). J. Climate, 30, 5419-5454, https://doi.org/10.1175/ JCLI-D-16-0758.1.

Haddad, Z. S., O. O. Sy, S. Hristova-Veleva, and G. L. Stephens, 2017: Derived observations from frequently sampled microwave measurements of precipitation-Part I: Relations to atmospheric thermodynamics. IEEE Trans. Geosci. Remote Sens., 55, 3441-3453, https://doi.org/10.1109/TGRS.2017.2671598.

Harris, G. N., K. P. Bowman, and D.-B. Shin, 2000: Comparison of freezing-level altitudes from the NCEP reanalysis with TRMM Precipitation Radar brightband data. J. Climate, 13, 4137-4148, https://doi.org/10.1175/1520-0442(2000)013<4137: COFLAF $>2.0 . \mathrm{CO} ; 2$.

Hirose, M., and K. Nakamura, 2004: Spatiotemporal Variation of the vertical gradient of rainfall rate observed by the TRMM Precipitation Radar. J. Climate, 17, 3378-3397, https://doi.org/ 10.1175/1520-0442(2004)017<3378:SVOTVG>2.0.CO;2.

Hotelling, H., 1936: Relations between two sets of variates. Biometrika, 28, 321-377, https://doi.org/10.1093/biomet/28.3-4.321.

Hu, Z., and R. C. Srivastava, 1995: Evolution of raindrop size distribution by coalescence, breakup, and evaporation: Theory and observations. J. Atmos. Sci., 52, 1761-1783, https:// doi.org/10.1175/1520-0469(1995)052<1761:EORSDB > 2.0.CO;2.

Huffman, G. J., and Coauthors, 2018: NASA Global Precipitation Measurement (GPM) Integrated Multi-satellitE Retrievals for GPM (IMERG). Algorithm Theoretical Basis Doc., version 5.2, 35 pp., https://pmm.nasa.gov/sites/default/files/document_files/ IMERG_ATBD_V5.2_0.pdf.

Iguchi, T., T. Kozu, R. Meneghini, J. Awaka, and K. Okamoto, 2000: Rain-profiling algorithm for the TRMM Precipitation Radar. J. Appl. Meteor., 39, 2038-2052, https://doi.org/ 10.1175/1520-0450(2001)040<2038:RPAFTT >2.0.CO;2.

, — - J. Kwiatkowski, R. Meneghini, J. Awaka, and K. Okamoto, 2009: Uncertainties in the rain profiling algorithm for the TRMM Precipitation Radar. J. Meteor. Soc. Japan Ser. II, 87A, 1-30, https://doi.org/10.2151/jmsj.87A.1.

Japan Meteorological Agency, 2018: Techniques of precipitation analysis and prediction for high-resolution precipitation nowcasts. Accessed 15 August 2018, 14 pp., https://www.jma.go.jp/jma/ en/Activities/Techniques_of_Precipitation_Analysis_and_ Prediction_developed_for_HRPNs.pdf.

Joyce, R. J., and P. Xie, 2011: Kalman filter-based CMORPH. J. Hydrometeor., 12, 1547-1563, https://doi.org/10.1175/JHMD-11-022.1.

Kobayashi, K., S. Shige, and M. K. Yamamoto, 2018: Vertical gradient of stratiform radar reflectivity below the bright band from the Tropics to the extratropical latitudes seen by GPM. Quart. J. Roy. Meteor. Soc., 144, 165-175, https://doi.org/ 10.1002/qj.3271.

Kubota, T., and Coauthors, 2017: Recent progress in global satellite mapping of precipitation (GSMAP) product. 2017 IEEE Int. Geoscience and Remote Sensing Symposium, Fort Worth, TX, IEEE, 2712-2715, https://doi.org/10.1109/ IGARSS.2017.8127556.

Kummerow, C. D., D. L. Randel, M. Kulie, N.-Y. Wang, R. Ferraro, S. Joseph Munchak, and V. Petkovic, 2015: The evolution of the Goddard Profiling Algorithm to a fully parametric scheme. J. Atmos. Oceanic Technol., 32, 2265-2280, https://doi.org/10.1175/JTECH-D-15-0039.1.

Muraki, Y., 2017: Concept of Asian Small Precipitation Radar Constellation. 68th International Astronautical Congress, Adelaide, 
Australia, International Astronautical Federation, IAC-17-B1.1.7, https://iafastro.directory/iac/archive/browse/IAC-17/B1/1/37216/.

Otsuka, S., and Coauthors, 2016: Precipitation nowcasting with three-dimensional space-time extrapolation of dense and frequent phased-array weather radar observations. Wea. Forecasting, 31, 329-340, https://doi.org/10.1175/WAF-D-150063.1.

Passive Microwave Algorithm Team Facility, 2018: GPROF2017 Version 1 and Version 2 (used in GPM V5 processing). Global Precipitation Measurement (GPM) Mission Algorithm Theoretical Basis Doc., 65 pp., http://rain.atmos.colostate.edu/ ATBD/ATBD_GPM_V5B_April15_2018.pdf.

Seto, S., T. Iguchi, N. Utsumi, M. Kiguchi, and T. Oki, 2013: Evaluation of extreme rain estimates in the TRMM/PR standard product version 7 using high-temporal-resolution rain gauge datasets over Japan. SOLA, 9, 98-101, https://doi.org/ 10.2151/sola.2013-022.

Tan, J., W. A. Petersen, G. Kirchengast, D. C. Goodrich, and D. B. Wolff, 2018: Evaluation of Global Precipitation Measurement rainfall estimates against three dense gauge networks. J. Hydrometeor., 19, 517-532, https://doi.org/10.1175/JHM-D17-0174.1.

Tanelli, S., and Coauthors, 2019: RainCube, the first spaceborne precipitation radar in a $6 \mathrm{U}$ CubeSat: From concept to mission. Ninth Conf. on Transition of Research to Operations, Phoenix,
AZ, Amer. Meteor. Soc., J1.3, https://ams.confex.com/ams/ 2019Annual/webprogram/Paper355100.htm.

Terao, T., and Coauthors, 2017: Direct validation of TRMM/PR near surface rain over the northeastern Indian subcontinent using a tipping bucket raingauge network. SOLA, 13, 157-162, https://doi.org/10.2151/sola.2017-029.

TRMM Precipitation Radar Team, 2011: Tropical Rainfall Measuring Mission (TRMM) Precipitation Radar algorithm instruction manual for version 7. JAXA/NASA, 175 pp., https:// www.eorc.jaxa.jp/TRMM/documents/PR_algorithm_product_ information/pr_manual/PR_Instruction_Manual_V7_L1.pdf.

Turk, F. J., Z. S. Haddad, P. Kirstetter, Y. You, and S. Ringerud, 2018: An observationally based method for stratifying a priori passive microwave observations in a Bayesian-based precipitation retrieval framework. Quart. J. Royal Meteor. Soc., 144, 145-164, https://doi.org/10.1002/ qj.3203.

Ushio, T., and Coauthors, 2009: A Kalman filter approach to the Global Satellite Mapping of Precipitation (GSMaP) from combined passive microwave and infrared radiometric data. J. Meteor. Soc. Japan Ser. II, 87A, 137-151.

Utsumi, N., and H. Kim, 2018: Warm season satellite precipitation biases for different cloud types over western North Pacific. IEEE Geosci. Remote Sens. Lett., 15, 808-812, https://doi.org/ 10.1109/LGRS.2018.2815590. 